others, though much improved, require more, and in these patients, after walting forty-eight hours, I give a further 60 or $80 \mathrm{c.cm}$.

This amount has been sufficient to cure some very severe cases, but a few of the worst may need a third or even a fourth dose. Some cases of the fulminating variety have been given 140 or $160 \mathrm{c.cm}$. serum within twenty-four hours of admission, but in these patients the first injection should, if possible, be given intravenously, for every moment saved is of vital importance.

In the majority of patients antidysentery serum acts like magic, but there are a very few in whom it seems only to have a slight beneficial effect. If four doses of $80 \mathrm{c.cm}$. each, spread over a period of six or seven days, have not brought about the desired result, I do not think further injections are indicated; consequently, I have nerer yet given wore than 320 c.cm.

As a general rule there is a distinct rise of temperature within twelve hours of the injection of the serum, and sometimes this may last forty-eight or seventy.two hours. I look upon this phenomenon as a good prognostic sign, for in all cases in which it has been well marked the patients have recovered rapidly. It is on account of this reaction, which may be rather severe, that I generally allow forty-eight hours to elapse between each injection of serum.

The onset of true serum disease has been most frequent on the seventh and eighth diys after the first injection. The severity of the symptoms has varied with the stock of serum in use. The patients hare complained of urticarial rashes, headaches, sore throats, arthritis, and oedema of the scrotum. They always have a rise of temperature, and five of them showed signs of cardiac dilatation. These symptoms have occurred in varying degrees of severity in 70 per cent. of the cases to whom serum has been given.

Results.

The results obtained in the cases I have treated along the lines above indicated may now be summarized. I have had altogether 456 definitely diagnosed cases. They are made up as follows:

One Hundred and Sixty Cases between August 30th and December 31st.-During this period the pressure of work was so great that it was impossible to keep notes of them all, and in consequence, although an accurate diagnosis of the type of dysentery present was made at the time, I am not now able to give exact figures.

Two Hundred aind Ninety-six Cases admitted from January $1 s t$ to May 31st.- - Of these 183 were acute bacillary cases and the remaining 113 were either chronic amoebic or bacillary. In this period only one case of acute amoebic dysentery was admitted.

In the flist 160 cases two deaths ocenrred. Both patients came from Gallipoli ; one a bacillary case, died the night of admission, and the other; who was a "mixed case," died of a perforated amoebic ulcer.

There were no deaths amongst the 113 chronic cases, but five were invelided to England and one to Cairo on account of perwere involided to England and one to Cairo on account of persistence of symptoms. Possibly others may have been

The 183 acute cases to which this paper particularly vefers were all bacillary, but in eight of these Entamoeba ristolytica was also present. In this series 69 mild cases did not have serum, 114 had serum. The mixed cases had emetine in addition.

One death only occurred. This was in an eniaciated patient aged 39, but who looked twenty years older. The attaek was of the fulminating variety, and although he improved a little after large doses of serum, hiccough set in, and he died after being eighteen days in hospital. The disonosis was verified post mortem.

After apparent recovery, 7 cases had a return of diarrhoea before they left the hospital. This, however, cleared up without specific treatment. One case definitely relapsed and required further injections of serum. One other case discharged to duty has since been readmitted. One case who refused serum and continued to pass blood and mucus indefinitely was sent to England. Eight other cases were also sent to England, but they were all convalescent.

They had all been severe cases, and it was thought inadvisable to subject them to an Egyptian summer. Of a total of $183 \mathrm{c}$ ises, it will thus be seen that in 173 the recovery wais so complete that they were considered fit for duty in Egypt." Apart from serum disease, the symptoms of which have already been described, there have been very few complications worth mentioning. Hiccough has occurred in 2 cases, intense tenesmus in 1 , retention of urine in 2 , persistent vomiting in 4 , herpes in 1 , tachycardia in 4 , pleurisy in 2 , acute rheumatism in 1 , enlargement of the liver in 2.

The offending germ has generally been the mannitefermenting type of dysentery bacillus.

The length of time in hospital varies with the severity of the disease. Nild cases may be discharged at the end of one month, others may require six to eight weeks before being fit for duty, and, finally, patients of the fulminating class may be three or four months, and can then only be considered convalescents.

The length of persistence of the acute symptoms is in inverse proportion to early diagnosis and early adminis. tration of antidysentery serum. If an ordinary case be diagnosed soon after admission the injection of serum will generally limit the acute stage to a period of four to nine days. I have had numerous cases in which one dose of $60 \mathrm{ccm}$. of serum has reduced, within a period of twenty. four hours after the injection, the number of stools fron about twenty to about four. Even although all blood has disappeared from the stools and the case appears convalescent within a few days of his admission, his subsequent complete recovery cannot be hurried, as the diet can only be very gradually increased.

When the patient comes under treatment in the stage in which the bacilli are attacking the intestine, the virulence and intensity of the symptoms are not of much moment, provided that they are accurately gauged and a correspondingly large dose of serum be given.

If, however, the severity of the case is underestimated or the patient be unfavourably situated for early treatment, serious damage may be done to the mucosa before au adequate dose of serum is given.

In these cases, when serum is finally injected, it cannot be expected to give such striking results. By killing all remaining active dysentery bacili it can prevent furthei sloughing, but the symptoms due to the ulceration already present will naturally only gradually abate.

\section{ON THE TREATMENT OF DYSENTERY.}

G. A. FINLAYSON, M.B.ABERD., M.R.C.P.Lond., Governarent Pathologibt, Singapore; late Captain R.A.M.C.(T.)

Thovgr stationed for the past year at a base hospital where the facilities afforded for the treatment of dysentery were excellent, I am fully alive to the difficulties which have to be faced at a field ambulance or casualty clearing station, but $I$ am still of opinion that a more active and vigorous treatnient of cases of acute bacillary dysentery is demanded in the early stages of the disease, more particularly by the exhibition of larger doses of antidysenteric serum than have usually been administered in the transferred cases. In the great majority "Mulford's" serum -was employed, and it seemed unfortunate that more attention was paid to the dosage prescribed in a "booklet" widely distributed than to the directions printed on the wrapper. A point naturally of great importance in early diagnosis is whether the patient has been infected by the specific amoeba or bacillus. A microscopical examination of the faeces should be made as soon as possible. There is no valid reason why a medical officer attached to a field ambulance and stationed where dysentery is likely to occur should not be supplied with a portable microscope provided with a $\frac{1}{8}$ in. objective ard No. 2 ocular; a brief demonstration of the more common intestinal protozoa would, it is needless to add, prove of inmense service.

Immediate treatment rests mainly on the microscopic finding, bearing in mind that one is dealing with the early stage of a primary attack. During the past six months only six cases of primary amoebic dysentery were admitted within two to three days of onset; all were discharged cured in less than three weeks. Emetine gr. $j$ hypodermically daily for ten days, or gr. $j$ hypodermically for six days in the morning, with gi. $\frac{3}{3}$ in a keratinecoated pill in the evening. Another case, transferred from Mesopotamia, had been given injections of tannic acid twice daily for seven weeks (the amount of tannio 
acid was not stated). On admission, active E. histolytica were demonstrated, and the patient was still passing blood and mucus. Within two days the amoebae had disap. peared, and within a week the motions had assumed a normal colour and consistence; no cyst was found on examination prior to discharge.

I am well aware that in all cases in which blood and an excess of slime are noted in the stool the inflammatory condition may not be cansed by the specific organisms. Having, however, formed the opinion on clinical grounds and from the microscopic appearances of the faeces that the case is one of bacillary dysentery, the question as to the treatment to be adopted arises. Recent results hare convinced me that $100 \mathrm{c.cm}$. antidysenteric serum should be given intravenously without delay, followed, if considered necessary, by a second dose within twenty-four hours. After one intravencus injection of $100 \mathrm{c.cm}$., sub sequent doses may be injected subcutaneously into the axilla, infraclavicular space, or flank. The amount which I usually gave was $40 \mathrm{c.cm}$. in the morning or evening. In association, a mixture containing magnesium sulphate $j j$, sodium sulphate $j \mathrm{j}$ to $\_$ss of water or mist. alba $z j$, was exhibited hourly, or even more frequently, until the motions became pale and watery, containing perhaps a few blood-stained shreds; the interval between the doses was then lengthened according to the conditions noted. Disregarding the rigor, which commonly followed the injection of serum, the temperature fell gradually to normal at periods varying from two to six days, the tongue cleaned rapidly, the stools became infrequent, tenesmus was practically absent, and the abdominal pains were alleviated. What was most striling was the intense relief afforded the patient in twenty-four to thirty-six hours after the commencement of the treatment. The diet in the carly stage was restricted to albumin water and barley water, with strained chicken tea and Brand's essence. In a series of 9 cases so treated recently :

2 received 200 c.cm. intrarenously.

received $100 \mathrm{c.cm}$. intravenousli.

1 received $100 \mathrm{c.cra}$. intra renously and $120 \mathrm{c.cm}$. sub cutaneously.

1 received $100 \mathrm{c.cm}$, intravenonsly and 80 c.cm. sub cutaneously.

3 received 100 c.cm. intrarenously and 40 e.cm. sub cutaueously.

Of these, 7 were infections by $B$. dysenteriae " $\mathrm{Y}$," one by a non-agglutinable strain, 2 by $B$. dysenteriae Shiga. Two cases which occurred in the surgical division (Captain C. W. Smith) are of interest in the determination of the incubation period.

\section{CASE T.}

Compound fracture of legt. Admitted September 13th, 1916. The onset of the attack of disentery occurred on September $23 \mathrm{rd}$; the infection was by the " $Y$ " bacillus; Widal positive 1. in 50. On September 24 th an injection of antidysenteric serum, i00 c.em., was given intravenously, followed by a similar dose on September 25th. On September z7th the bowels acted twice and the stool was seraiformed and yellow; the temperature wass normat. Convalescence was rapid. In this case the incubation preriod was at least nine clear days.

$$
\text { CASE II. }
$$

Almitted on Octoher 2nd, 1916, two dars after an operation for radical cure of hernia. 'The onset of dysentery occurred on October 7 th. Non-agrlatinable " $Y$ " isodated; Widal positive October 7th. Non-agg, "On October 9 th an injection of $100 \mathrm{ccc}$. 1 in 50 Shiga and "I." On October 9th an injection of 100 c.cm. antidysenterio serum was made intravenously, followed by a
secoud dose on October 11 th. On October 12th the bowels acted second dose on October 11th. On October 12th the bowels acted
twice in tiventy-four hours, and on October 13th there was no twice in tiventy-four hours, and on october 13th there was no Recorery was uninterrupted.

The incubation period in this case was six clear days. Both cases were admitted from out-stations where cases of dysentery lad occurred. No further case was noted in the division during the period the patients were in hospital.' Neither shorred any urticarial ertiption.

Rarely was an opportunity afforded of following a case after discharge, bnt the following case is an exception:

$$
\text { CASF IIT. }
$$

Ailmitted on Juls 25th, 1916, with a history of onset twelve hours previousty. "Y" bacilins isclated; Widal positive 1 in 50 Shiga. 100 c.cm. antickysenteric serum was given intravenously, and 40 c.cm. subcutaneously on Iuly 26 th. By August 5 th he was on full diet, and on Augist loth he was discharged to duts. He was 5 th he reported that he had wit on $7 \mathrm{lb}$. during the previous month; he looked fit and wol!.
When I was relieved of duties on November 8th, 1916. all cases lad either returned to duty or were quite conralescent.

Ricsults Obtained by Subcutaneous Trijection onty.

This series comprises 22 cases admitted to hospital with a prinary attack-
3 within twenty-four hours of onset of disease.
6 on the second day after onset of disease.
7 on the third day after onset of disease.
3 on the fourth day after onset of disease.
3 on the fifth day after onset of disease.

Ten others had relapsed or had been transferred from a stationary hospital or elsewhere ${ }_{2}$ where they, had been under treatment for some days or perhaps weeks. In the first named gronp the amount of serum administered was on an average $125 \mathrm{c.cm}$., varying from $80 \mathrm{c.cm}$. to $200 \mathrm{c.cm}$, except in one ease, which received $20 \mathrm{c.cm}$. only; in the other group the dosage was on an average $80 \mathrm{c.cm}$., varying from $20 \mathrm{c.cm}$. to $150 \mathrm{c.cm}$. $\dot{B}$. dysenteriae Shiga was isolated in 9, the " $\mathrm{Y}$ " bacillus in 4 . Serum diagnosis was reliec upon in 12 other cases, being positive 1 in 50 or over Shiga in 8 , positive 1 in 50 or over " $Y$ " in 4 . In 6 others the serum reaction was positive to Shiga 1 in 20 only.

Of those patients admitted with a primary attack, 3 were under treatment withir three days of the onset, and received 80 c.cm., 100 c.cm., and 160 c.cm. serum respectively. Later it was considered advisable to invalid them to England for further treatment as a sigmoidoscope examination of the lower gut revealed the presence of numerous indolent ulcors. Blood and slime continued to be passed at irregular intervals, though the general condition of each seemed unaffected by the catarrhal condition, and there was a gradual gain in weight prior to transfer. The remainder were discharged to duty or to a convalescent dépôt, the average duration of stay in hospital being one month.

Treatment by Sulphates.

Occasionally the statement is heard that cases do just as well on saline purgatives alone without the injection of any specific serum. No doubt in a percentage of cases of the bacillary type, perhaps in " $\mathrm{Y}$ " infections more particularly, the condition clears up on the administration of the sulphates. What medical officer, however, deems himself so astute that at the ontset of an attack he can foretell that the infection will prove of a mild character and that it will not prodnce ulceration which may become chronic? In a series of eleven prtients, transifered as convalescent from a stationary hospital or elsewhere, no serum appeared to have been injected though sereral had receired numerous doses of emetine. A specific bacillas was isolated from the stool in font instances-in three, " $Y$ " bacillus; in one, Shiga's bacillus. The serum reaction was relied npon in a further seren, being positive 1 in 50 " $Y$ " in one, positive 1 in 50 or over Shigg in six. After further treatment all were discharged seve one invalided to England.

\section{Codplications}

The urticarial rash, which constantly appeared after a subcutaneous injection, was at times most profuse and distressing to the patient. Carbolic acid 1 in 20 , calamine lotion, or lead and opium lotion appeared to allay the itching. In one case there was a distinct febrile attack, with marked headache, which readily yielded to aspinin in small doses.

Synoritis was observed in two cases, which had receired $130 \mathrm{c.cm}$. and $200 \mathrm{c.cm}$. serum respectively into the sub. cutaneous tissues (on the tenth day after the first injection). In the one the knee-joints, in the other the left shoulder and small joints of the fingers were inrolved. In the former there was a considerable amount of effusion, with pain and tenderness, and a marked rise in temperature. The condition in each quickly cleared up nnder the ad. ministration of sodium salicylate gr. $\mathrm{x} v$ every four hours. One somewhat debilitated patient dereloped a late abscess following an injection of $40 \mathrm{c.cm}$. into the infraclaricular region. Staphylococcus atbus was isolated from the pus in pure culture. The abscess was opened and drained, and the wound healed rather slowly. 


\section{Bacteriological Results.}

Occasionally it may appear diffieult to reconcile a series of negative results reported by the bacteriologist with the clinical opinion. In one instance five successive specimens were plated before a suspicious colony was picked off, and shown to be the specific bacillus. In other cases, in which an organism was isolated in the early stage of the disease, further bacteriological examinations were almost uniformly negative, though the patients, after treatment, still exhibited nlceration of the lower gut attended by the passage of blood-stained mucus. A positive Widal reaction of 1 in 50 or over frequently confirmed me in the opinion that the case was one of bacillary dysentery, though the examination of the stool was negative. On the other hand, on two occasions the " $\mathrm{Y}$ " bacillus was isolated when the serum reaction was 1 in 20 only, and in one instance Shiga's bacillus was obtained when the serum of the patient did not agglutinate the organism even in that low dilution. The strains isolated conformed with the usual sugar reactions, etc., and were tested against specitic agglutinating serums of high titre. In what position is one to place inagglutinable strains? In one case the serum of the patient produced clumping of his own strain in the dilution of 1 in 20 when with specific " $\mathrm{Y}$ " serum no agglutination was observed in the same dilution.

Dysentery Carriers.

Two convalescent patients, transferred, were admitted, showing no signs or symptoms. Each had been on full diet for some days and the stools were formed and natural. The Widal reaction was positive 1 in 50 Shiga. In the course of the routine bacteriological examination before discliarge Shiga's bacillus was isolated, in one from the first specimen sent, in the other from the second. From three subsequent samples, taken after the administration of a saline purge, no bacillus was isolated in either case and the individuals were discharged.

I beg to express my sincere thanks to Captains C. W. Smith, R.A.M.C., and J. D. Graham Stewart, R.A.M.C., for lindly assistance.

\section{THE IMPOR'TANCE OF THE EARLY PROPHY- IACIIC INJECTION OF AN'TITETANIC SERUM IN “'TRENCH FOOT." \\ BY \\ Surgeon-General Sir DAVID BRUCE, C.B., F.R.S.}

CAses of tetanus following on "trench foot" have lately been numerous. On account of the hurt not being of the nature of an ordinary gunshot or shell wound they have not, until quite lately, received the usual prophylactic dose of antitetanic serum at the front. For the same reason, it may be supposed, they have not received the later prophy. lactic doses which have been so strongly recommended by the Committee of the War Office for the Study of Tetanus in their memorandum published in the BrItrish Medical Journal on November 1.1th, 1916.

During the last few woeks tifteen cases - of tetanus ciused by "trench foot" have been reported, but full reports, giving the result, have only been received in eight. The following table gives the outstanding features of these eight cases. A prophylactic injection was not given in any of them.

\begin{tabular}{|c|c|c|c|c|}
\hline No. & Incubation. & $\begin{array}{l}\text { Duration of } \\
\text { Disease. }\end{array}$ & Died. & Recovered. \\
\hline$\underline{1}$ & 12 days & 2 days & + & \\
\hline 2 & $12 \ldots$ & & & + \\
\hline 3 & $24 \quad$, & 2 & + & \\
\hline 4 & $?$ & $2 "$ & + & \\
\hline 5 & 15 days & 1 & + & \\
\hline 6 & $?$ & 1. & + & \\
\hline 7 & 16 days & & & + \\
\hline 8 & 14 & 5 " & + & \\
\hline
\end{tabular}

From this table it will be seen that of the eight cases only two recovered, and the average duration of the disease was only 2.5 days. This is a return to the picture of tetanus familiar before prophylactic injections were introduced. The disease wastes no time in local manifestations, but bursts out as generalized tetanus and runs its acute and fatal course in twenty-four to forty-eight hours.

It is to be hoped that no medical officer in charge of a case of "trench foot" will hesitate for a moment in giving a prophylactic injection of antitetanic serum, and repeat the same at intervals of seven days until the wounds are clean. If something is not done speedily, these cases of tetanus following on "trench foot" will run up in a most disastrous way the rate of mortality in tetinus, which every one, by the use of prophylactic and early therapeutic antitetanic serum, is trying to lower.

\section{ettentaranda:}

\section{MEDICAL, SURGICAL, OBSTETRICAL.}

\section{AN OVARIAN CYST COMMUNICATING BY A VALVULAR CANAL WITH THE} FALLOPIAN TUBE.

ON August 26th I removed intact, from a patient aged 34, a small cystic tumour, firmly and extensively adherent in the pelvis. The Fallopian tube, like a pyriform pod, dilated at its fimbriated end to the size of the index finger, was seen coursing the surface of the ovarian cyst. The tube looked like an ordinary hydrosalpinx, and on compressing it clear limpid fluid flowed from its cut nterine end. It was then observed that the ovarian cyst was gradually decreasing in size and that the Fallopian tube remained semi-distended. The ovarian cyst was then opened; and at a spot about two inches from the uterine end of the Fallopian tube there was observed in the cyst wall 'a crescentic fold, guarding, as it were, a canal of "about an inch in length, which opened directly into the tube. The fluid in the cyst presented exactly the same appearance as the fluid which flowed at first from the tube.

I have never before seen a tubo-ovarian tumour of this character. I have heard that ovarian or tubal cysts have been known to empty themselves through the riterus. - In the case here described there secms to be no reason apparently why fluid did not escape from the tumour by the uterus, for the uterine end of the Fallopian tube seemed to be quite normal and allowed the fluid to pass, in, it is true, an extremely small stream.

London, w. Jayes Oliver, M.D., F.R.S.Edin.

THE TREATMENT OF CANCER BY CUPRASE.

A woman not long past the menopause liad four year's previously undergone a radical operation for carcinoma of the right breast, which had evidently been very extensive. 'There was no local recurrence either in the scar or on the chest wall, but there was some involvement of the mediastinum, causing pressure both on the trachea and oesophagus, and also implicating the vagus and sympe. thetic nerves on the right side; some enlarged glands were to be felt above the clavicle on both sides. $X$ rays had been tried for a time, but without apparent benefit, and the patient had become too weak to undergo the exertion of transport to the radiologist. The prognosis was, of course, hopeless, and alleviation of suffering appeared to be the utmost that medical science or art could offer.

It was at this stage that cuprase suggested itself, if the advertisements and reports supplied by its makers were to be credited, as worthy of trial; at least, according to the reports, and especially to Dr. Herschell's eulogistic state ments, it could do no harm. The matter was explained to the patient and her relatives, and although, of course, I would promise nothing in the way of cure, they decided it should be tried. Accordingly I obtained a box of eight ampoules (price 25s.), no less amount being supplied, and no "trial sample" being permitted. I injeoted the contents of one ampoule according to directions. Not only was the injection immediately painful, but there was very marked local reaction-pain, redness, heat, and swellingwhich persisted for nearly a week and caused the patient a large amount of suffering. . Not only was there marked local pain, but the patient's general condition was much 